\title{
BMJ Open Antibiotic prescriptions for inpatients having non-bacterial diagnosis at medicine departments of two private sector hospitals in Madhya Pradesh, India: a cross-sectional study
}

\author{
Kristoffer Landstedt, ${ }^{1}$ Ashish Sharma, ${ }^{2}$ Fredrik Johansson, ${ }^{1}$ \\ Cecilia Stålsby Lundborg, ${ }^{1}$ Megha Sharma ${ }^{1,3}$
}

To cite: Landstedt $\mathrm{K}$, Sharma A, Johansson F, et al. Antibiotic prescriptions for inpatients having non-bacterial diagnosis at medicine departments of two private sector hospitals in Madhya Pradesh, India: a cross-sectional study. BMJ Open 2017;7:e012974. doi:10.1136/bmjopen-2016012974

- Prepublication history for this paper is available online. To view these files please visit the journal online (http://dx.doi.org/10.1136/ bmjopen-2016-012974)

CSL and MS share last authorship.

Received 7 June 2016

Revised 18 November 2016 Accepted 15 December 2016

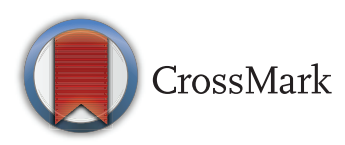

For numbered affiliations see end of article.

Correspondence to Dr Megha Sharma; meghasharma27@rediffmail. com

\section{ABSTRACT}

Objectives: To present and compare antibiotic prescribing for inpatients among the most common non-bacterial diagnoses groups at medicine departments of a teaching (TH) and a non-teaching hospital (NTH) in central India.

Setting: An observational cross-sectional study was conducted at two tertiary care settings in Ujjain district, Madhya Pradesh, India.

Data and participants: The data were collected manually, using a customised form. Complete records of all inpatients, who were $>15$ years of age and had stayed for at least one night in either of the hospitals during 2008-2011, were analysed.

Outcome measures: Inpatients were grouped according to the presence or absence of a bacterial infectious diagnosis, viral/malaria fever or cardiovascular disease. Classes of antibiotics prescribed to these groups and adherence to the available prescribing guidelines were compared between the hospitals using the notes from the patient files and the diagnoses.

Results: Of 20303 inpatients included in the study, $66 \%$ were prescribed antibiotics. Trade name prescribing and use of broad-spectrum antibiotics were more frequent at the NTH than at the TH $(p<0.001)$. At the $\mathrm{TH}$ a significantly higher proportion of patients having fever without registered bacterial infection were prescribed antibiotics (82\%) compared with the NTH $(71 \%, p<0.001)$. Patients admitted for cardiovascular diagnosis without registered bacterial infections received antibiotic prescriptions at both hospitals (NTH 47\% and TH 37\%) but this was significantly higher at the NTH $(p<0.001)$. None of the diagnoses were confirmed by microbiology reports.

Conclusions: Prescribing antibiotics, including broad-spectrum antibiotics, to inpatients without bacterial infections-that is, viral fever, malaria and cardiovascular disease, was common at both hospitals, which increases the risk for development of bacterial resistance, a global public health threat. In view of the overprescribing of antibiotics, the main recommendations are development and implementation

\section{Strengths and limitations of this study}

- A prospective study over a period of 3 years and inclusion of all patients, irrespective of their age and sex, strengthens the representativeness of the results and obviates seasonal variations.

- Data-collecting tools were same at both study hospitals and the staff who collected the data were trained by the same person at both locations to minimise variances.

- An observational non-interventional study design might have minimised the effect on the prescribers of being observed and audited.

- All possible efforts were made to minimise the risk of missing data by continuous monitoring and cross-checking of the data. However, some data-for example, a few diagnoses, might have been lost during translation from analogue to digital records.

- A large proportion of patients were categorised as belonging to the suspected bacterial diagnosis groups. Some of these diagnoses might have been categorised as non-bacterial if the aetiology had been confirmed by microbiology reports. This could have contributed to even higher antibiotic prescribing rates in the non-bacterial diagnoses group. However, owing to the absence of confirmed aetiology and the observational design of the study this was not possible.

of local prescription guidelines, encouragement to use laboratory facilities and prescription analysis, with antibiotic stewardship programmes.

\section{BACKGROUND}

Increasing morbidity and mortality due to infectious diseases, despite the availability of lifesaving antibiotics, is an alarming global situation. ${ }^{1}$ The incidence of mortality due to 
infections is higher in low- and middle-income countries than in high-income countries. ${ }^{2-4}$ The World Health Organization (WHO) has reported a high burden of communicable diseases in India and infections are responsible for $28 \%$ of the total mortality in the country. ${ }^{5}$ Additionally, antibiotic resistance in India is reported to be high. However, figures cannot be generalised to all Indian settings as the bacterial resistance patterns vary widely between its regions and settings and most studies so far have been relatively limited. ${ }^{7}$

Over- and underuse of antibacterial agents is a global concern. It results in unnecessary treatment costs, is a potential risk for the development of antibiotic resistance and results in side effects such as antibioticassociated diarrhoea caused by Clostridium difficile or gastroenteritis. ${ }^{8}$ According to a report, the global consumption of antibiotics increased by $36 \%$ between 2000 and 2010; five countries-Brazil, Russia, India, China and South Africa-accounted for $76 \%$ of this increase. ${ }^{9}$ Despite the paucity of studies that describe antibiotic prescribing in India, Van Boeckel et $a t^{\theta}$ presented India at the top of the list of antibiotic consumption with $12.9 \times 10^{9}$ units in 2010 , where one unit indicates a pill, capsule or ampoule. ${ }^{1}$ On the one hand, this increase might mean that sections of the population that previously had no access to antibiotics can now access them, but on the other, the fact that antibiotic resistance is a consequence of antibiotic use cannot be ignored. ${ }^{10}$

It is thus imperative to map local prescribing patterns of antibiotics in order to examine the need for improvement and to counter the consequences of their inappropriate prescription. The Indian private sector is the major healthcare provider but little is known about its prescribing patterns. ${ }^{11-14}$

\section{OBJECTIVES}

The study was conducted to present, analyse and compare antibiotic prescribing to inpatients enrolled for the most common non-bacterial diagnoses at the medicine departments of a teaching (TH) and a nonteaching hospital (NTH) in central India.

\section{METHODS}

Study design

A cross-sectional observational design was used.

\section{Setting}

The study was conducted at the medicine departments of two tertiary care hospitals (one TH and one NTH) from the private sector in Ujjain district, India, both of which are run by the same trust. The TH is located in a rural area of Ujjain district and had 570 beds at the time of the study. The NTH is located in the central part of Ujjain city and had 350 beds at the time of the study. The TH provides medical services, including medical treatment and free-of-charge medicines, to all patients, whereas the NTH charges for the medical facilities on a 'no profit-no loss' basis. Patients at the NTH have to buy prescribed medicines from the pharmacies inside or outside the hospital. The physicians at the $\mathrm{TH}$ are paid a salary and have no direct contact with sales representatives of pharmaceutical companies. Furthermore, the management at the TH is responsible for the purchase and supply of the drugs.

The hospital level essential medicine list was available in written form at the TH but no specific implementation activities were conducted during the study period. Local prescribing guidelines were not present at any of the hospitals. Almost all physicians practising at the NTH also undertook private practice and could be easily contacted by representatives of pharmaceutical companies. Payments of the physicians at the NTH increase above normal according to the number of patients they admit to the hospital and the number of visits they make to inpatients. Both the TH and the NTH are tertiary care hospitals with a number of specialty departments, such as paediatrics, obstetrics and gynaecology, surgery, orthopaedics, pulmonary medicine and so on, which treat specific patients. For example, patients presenting with symptoms related to lungs and chest (other than heart) visit the pulmonary medicine department. A wellequipped microbiology laboratory was present to process the samples free of cost for all patients from the TH and with nominal charges for those from the NTH.

\section{Participants}

Inclusion and exclusion criteria

Patients who stayed for at least one night at medicine departments of either of the two hospitals were considered as inpatients and included in the study. Patients who had incomplete records or were admitted to the medical intensive care units within the medicine departments were not included in the analysis. Treatment recommendations, including dose and frequency, differ for patients less than 15 years of age and the defined daily dose (DDD) measurement is not applicable to them, thus they were also excluded. ${ }^{15}$

\section{Variables}

Patient information was analysed for age, sex, diagnosis, duration of hospital stay, if they received antibiotic treatment and duration of antibiotic treatment. Prescriptions were analysed for the type of antibiotics prescribed, their dose and frequency. The antibiotics were classified according to the Anatomical Therapeutic Chemical (ATC) classification of the WHO Collaborating Centre for Drug Statistics Methodology (WHOCC). ${ }^{16}$ DDDs were calculated for all prescribed antibiotics. ${ }^{16}$ DDD is a technical unit used for comparison and is the average daily dose of a specific drug for its main indication in adults. ${ }^{15}$ Fixed-dose combinations (FDCs) of antibiotics that did not have an ATC code assigned by WHOCC were assigned the code 'J01RA*' according to Sharma et $a l .{ }^{17}$ FDCs that did not have a DDD were assigned one by examining the constituents and the proportions in 
which they were found in one unit dose. The DDD was then calculated on the basis of the number of units and converted to a dose in grams. The total number of antibiotics prescribed during a hospital stay was counted for each patient and was designated 'prescribing occasions'.

The National List of Essential Medicines of India (NLEMI) is based on the WHO List of Essential Medicines (WHOLEM) and adapted to the spread of disease in India. ${ }^{18}$ These lists serve as guidelines to promote the prescription of safe, cheap and effective drugs to the population. ${ }^{18} 19$ Adherence to these lists was evaluated for all prescriptions.

\section{Data sources and considerations}

The data collection process is described in detail elsewhere. ${ }^{13}{ }^{14}$ In brief, the study was conducted prospectively between 1 April 2008 and 31 March 2011. Patient throughput in the $\mathrm{TH}$ and the NTH amounted to 29026 and 41561 patients, respectively. The data were manually collected by the nurses using a specially designed form attached to the patient's file at the medicine department of the TH and the NTH. All patients were included to minimise the possibility of selection bias. Every admission in the department was considered as a new patient. The nurses and new recruits were trained regularly for the data collection by the last author (MS). The data collection form was updated daily based on a patient's day-to-day progress. All notes written in the patient files by the treating consultant were recorded and included for the analysis. It was possible that a patient could have more than one diagnosis. Therefore all indications, diagnoses and/or symptoms recorded in the patient files were transferred to the data collection form. The data were translated to digital data files using Epidata software 3.1 (http://www.epidata.dk/ download.php) and Microsoft Excel. Two specifically trained data entry operators translated the diagnoses in accordance with the 'International Classification of Diseases' (ICD-10 codes) and the generic names of the prescribed antibiotics were translated to WHO-assigned ATC codes and DDDs per day. ${ }^{15} 2021$

In order to exclude all cases of clinically suspected bacterial infection and following the aim of the study, best possible efforts were made to distinguish those patients who had any indications, even for secondary antibiotic prophylaxis, from those who did not. ${ }^{22-24}$ The patients were categorised into three main groups using the diagnoses registered in the patient files and the ICD-10 codes: group (a) cardiovascular diseases, (b) non-bacterial fevers and (c) all diagnoses other than group (a) and (b), including all types of bacterial infection. Sixty-seven per cent of patients in the TH and $75 \%$ in the NTH were included in group (c). All cases of chronic obstructive pulmonary disease (COPD) were also included in group (c). Although the aetiology of the disease was seldom specified in the records, these patients with COPD should receive less restricted antibiotic treatment.
Groups (a) and (b) were selected for a detailed study of antibiotic prescribing for non-bacterial diagnoses in accordance with the study aim. In group (a), hypertension, acute myocardial infarction and valvular heart disease were the most common diagnoses. In group (b) different types of malaria and cases of viral fever (ICD code-B34.9) were included. These non-bacterial fevers were common in both study settings. It has previously been reported that a large number of antibiotics are prescribed to patients with malaria or viral fever in malaria endemic countries like Uganda (figure 1). ${ }^{25}$ Moreover, groups (a) and (b) comprised the largest homogeneous patient groups in our study settings.

These groups were further divided into four subgroups to identify and analyse the patients exclusively having non-bacterial diagnoses corresponding to our study aim. Cardiovascular group (group a) was divided into two subgroups: 'cardiovascular diseases with no registered bacterial infection' (subgroup 1) and 'cardiovascular diseases with suspected bacterial infection' (subgroup 2). Similarly, the non-bacterial fever group (group b) was divided into 'malaria or viral fever with no registered bacterial infection' (subgroup 3) and 'malaria or viral fever with suspected bacterial infection' (subgroup 4, figure 1).

All patients with rheumatic heart disease (RHD) were categorised in subgroup 2 or in subgroup 4 to rule out all possible bacterial infection as a confounder, since the WHO guidelines for secondary prevention after rheumatic fever set the duration of preventive antibiotic treatment from 5 years up to lifelong, depending on a number of factors-for example, time since the last episode of rheumatic fever and severity of valve engagement, and support an individual assessment of every case. $^{22} 23$

An antibiotic prescribed for a day was considered as one prescribing occasion. Prescribed DDDs were calculated per 1000 patients. According to WHOCC, oral metronidazole (P01AB01) is coded as an antiprotozoal drug, but is coded as an antibacterial agent in the NLEMI. Therefore it was considered as an antibacterial agent in this study. ${ }^{18}$

\section{Ethics statement}

Being an observational study, the data collection did not interfere with the treatment or cause any additional risks for the patients. Moreover, the names of the prescribers were not recorded to minimise the effect of being observed. All patients were assigned a unique code during the data entry to maintain anonymity of the inpatients. This unique code was used to compare details of patient information and antibiotic prescriptions for the analysis. The data were collected at the individual level for all inpatients and were linked to each patient with the assigned unique codes instead of, for example, social security number. However, the analysis was conducted at group level to maintain confidentiality. 


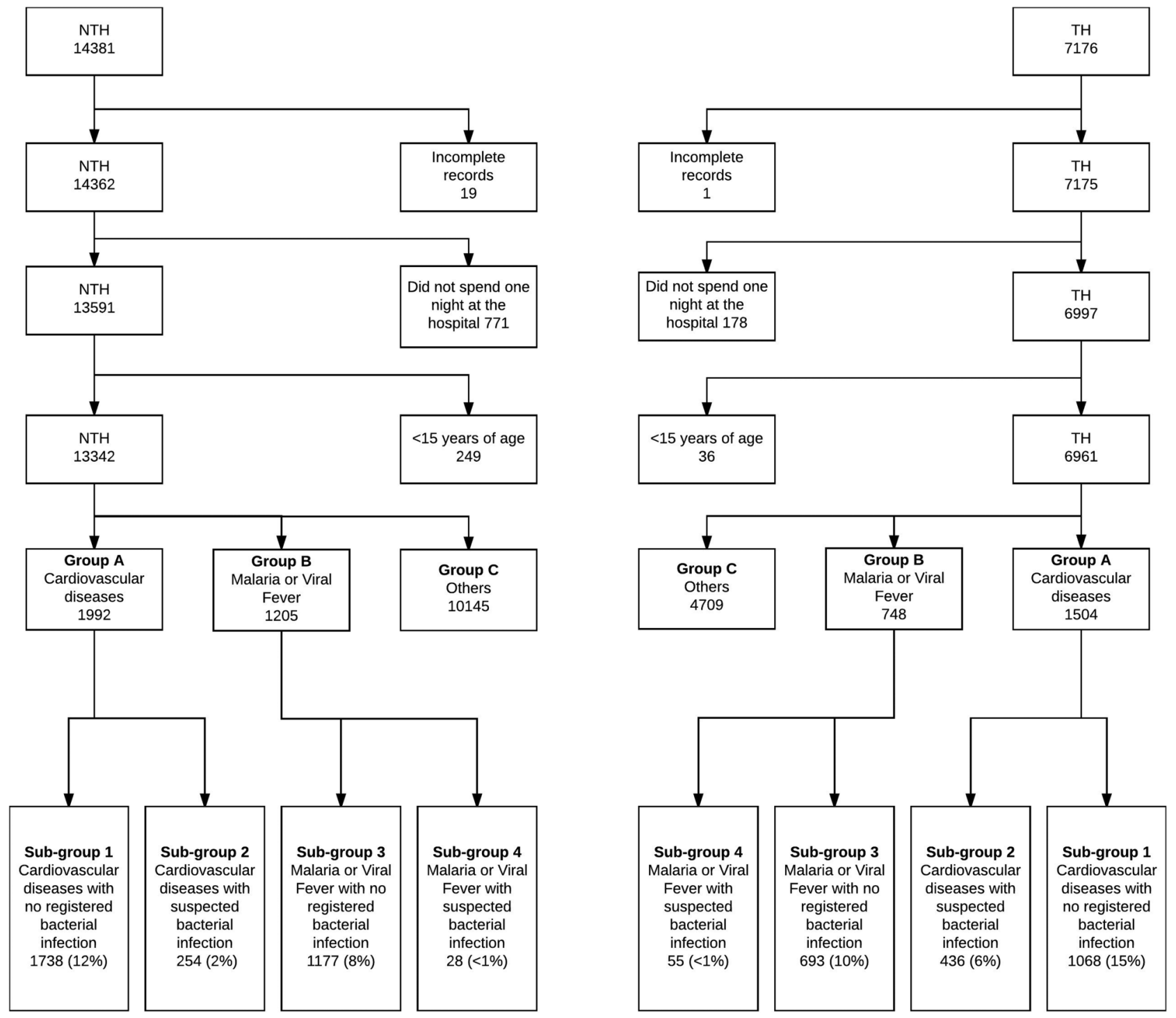

Figure 1 The process of selection and grouping of inpatients admitted to medicine departments of the teaching hospital (TH) and the non-teaching hospital (NTH) based on their diagnosis.

The ethics committee of Ruxmaniben Deepchand Gardi Medical College, Ujjain, approved the study with approval number: $41 / 2007$.

\section{Statistical methods}

All frequencies and percentage of categorical values were calculated. Sum, median, mean, range and SD were calculated for continuous numerical values. Values were rounded to the closest whole number for percentage, prescription tables and in the text. The independent t-test was used for comparison of normally distributed and continuous variables. The $\chi^{2}$ test was used for comparison of categorical values. Fisher's exact test was used for expected values $<5$ and Pearson's $\chi^{2}$ test was used for expected values $>5$. Bonferroni's correction for multiple comparisons was used and $p$ values $<0.001$ were chosen for significance level to minimise the risks of type one errors. The data were analysed with Excel, SPSS V.22 (SPSS, Chicago,
Illinois, USA) and STATA V.13.1 (Stata Corp, College Station, Texas, USA).

\section{RESULTS}

During the study period, a total of 21557 patients were admitted to the two medicine departments, 7176 patients to the TH and 14381 to the NTH (figure 1). Of those admitted, records of 20 patients were incomplete, $949(4 \%)$ stayed less than one night and 285 patients $(1 \%)$ were aged $<15$ years. Therefore, in accordance with the inclusion criteria, 1254 patient records were excluded and 20303 (94\%) records were included for further analysis (6961 at the TH and 13342 at the $\mathrm{NTH}$, figure 1).

The most common diagnoses in the $\mathrm{TH}$ were COPD $(10 \%)$, viral fever $(7 \%)$ and hypertension $(5 \%)$ and in the NTH were viral fever $(10 \%)$, malaria $(6 \%)$ and COPD (5\%, table 1). Antibiotics were prescribed to 
Table 1 Number of inpatients in four diagnoses Subgroups at medicine departments of one teaching and one non-teaching hospital in Ujjain, India

\begin{tabular}{|c|c|c|c|c|c|c|c|c|c|c|c|}
\hline \multicolumn{3}{|c|}{$\begin{array}{l}\text { Cardiovascular with no registered } \\
\text { bacterial infection Subgroup } 1\end{array}$} & \multicolumn{3}{|c|}{$\begin{array}{l}\text { Cardiovascular with suspected } \\
\text { bacterial infection Subgroup } 2\end{array}$} & \multicolumn{3}{|c|}{$\begin{array}{l}\text { Malaria or viral fever with no registered } \\
\text { bacterial infection Subgroup } 3\end{array}$} & \multicolumn{3}{|c|}{$\begin{array}{l}\text { Malaria or viral fever with } \\
\text { suspected bacterial infection } \\
\text { Subgroup } 4\end{array}$} \\
\hline Diagnosis group & $\begin{array}{l}\text { TH } \\
\text { n (\%) }\end{array}$ & $\begin{array}{l}\text { NTH } \\
\text { n (\%) }\end{array}$ & $\begin{array}{l}\text { Diagnosis } \\
\text { group }\end{array}$ & $\begin{array}{l}\text { TH } \\
\text { n (\%) }\end{array}$ & $\begin{array}{l}\text { NTH } \\
\text { n (\%) }\end{array}$ & Diagnosis group & $\begin{array}{l}\text { TH } \\
\text { n (\%) }\end{array}$ & $\begin{array}{l}\text { NTH } \\
\text { n (\%) }\end{array}$ & Diagnosis group & $\begin{array}{l}\text { TH } \\
\text { n (\%) }\end{array}$ & $\begin{array}{l}\text { NTH } \\
\text { n (\%) }\end{array}$ \\
\hline Total & 1068 & 1738 & Total & 438 & 254 & Total & 693 & 1177 & Total & 55 & 28 \\
\hline Hypertension & 328 (31) & $470(27)$ & COPD & $209(48)$ & $77(30)$ & Malaria & 237 (34) & $872(74)$ & COPD & $10(18)$ & $5(18)$ \\
\hline $\begin{array}{l}\text { Cerebrovascular } \\
\text { accident }\end{array}$ & $126(12)$ & $383(22)$ & $\begin{array}{l}\text { Rheumatic heart } \\
\text { disease }\end{array}$ & $130(30)$ & $102(40)$ & $\begin{array}{l}\text { Cerebral malaria } \\
\text { caused by } \\
P . \text { falciparum }\end{array}$ & $4(1)$ & $11(1)$ & $\begin{array}{l}\text { Urinary tract } \\
\text { infection }\end{array}$ & $5(9)$ & $7(25)$ \\
\hline $\begin{array}{l}\text { Acute myocardial } \\
\text { infarction }\end{array}$ & $28(3)$ & $202(12)$ & $\begin{array}{l}\text { Pulmonary } \\
\text { tuberculosis }\end{array}$ & $19(4)$ & $18(7)$ & $\begin{array}{l}\text { Malaria caused by } \\
\text { P. falciparum UNS }\end{array}$ & $9(1)$ & $9(1)$ & Typhoid fever & $8(15)$ & $2(7)$ \\
\hline $\begin{array}{l}\text { Chronic ischaemic } \\
\text { heart disease }\end{array}$ & $17(2)$ & $189(11)$ & $\begin{array}{l}\text { Urinary tract } \\
\text { infection }\end{array}$ & $17(4)$ & $15(6)$ & $\begin{array}{l}\text { Malaria caused by } \\
P \text {. vivax UNS }\end{array}$ & $16(2)$ & $61(5)$ & $\begin{array}{l}\text { Acute } \\
\text { gastroenteritis }\end{array}$ & $4(7)$ & $6(21)$ \\
\hline $\begin{array}{l}\text { Coronary artery } \\
\text { disease }\end{array}$ & $98(9)$ & $101(6)$ & $\begin{array}{l}\text { Acute } \\
\text { gastroenteritis }\end{array}$ & $14(3)$ & $12(5)$ & Malaria UNS & $208(30)$ & 791 (67) & $\begin{array}{l}\text { Disease of } \\
\text { airways UNS }\end{array}$ & $8(15)$ & $0(0)$ \\
\hline Left ventricle failure & $44(4)$ & $69(4)$ & $\begin{array}{l}\text { Lower airway } \\
\text { infection UNS }\end{array}$ & $13(3)$ & $0(0)$ & Viral fever & $456(66)$ & 305 (26) & $\begin{array}{l}\text { Disease of upper } \\
\text { airways UNS }\end{array}$ & $7(13)$ & $0(0)$ \\
\hline $\begin{array}{l}\text { Congestive heart } \\
\text { failure }\end{array}$ & $56(5)$ & 39 (2) & Sepsis & $0(0)$ & $5(2)$ & & & & $\begin{array}{l}\text { Pulmonary } \\
\text { tuberculosis }\end{array}$ & $4(7)$ & $2(7)$ \\
\hline $\begin{array}{l}\text { Dilated } \\
\text { cardiomyopathy }\end{array}$ & $79(7)$ & $6(<1)$ & HIV with infection & $8(2)$ & $1(<1)$ & & & & HIV with infection & $2(4)$ & $0(0)$ \\
\hline $\begin{array}{l}\text { Unspecified } \\
\text { cardiomyopathy }\end{array}$ & $21(2)$ & $54(3)$ & Rheumatic fever & $1(<1)$ & $4(2)$ & & & & $\begin{array}{l}\text { Rheumatic heart } \\
\text { disease }\end{array}$ & $2(4)$ & $1(4)$ \\
\hline $\begin{array}{l}\text { Multiple valve } \\
\text { disease }\end{array}$ & $61(6)$ & $7(<1)$ & Endocarditis & $0(0)$ & $4(2)$ & & & & $\begin{array}{l}\text { Pelvic } \\
\text { inflammatory } \\
\text { disease }\end{array}$ & $2(4)$ & $0(0)$ \\
\hline Angina pectoris & $10(1)$ & 35 (2) & Pneumonia & $1(<1)$ & $4(2)$ & & & & Pneumonia & $0(0)$ & $1(4)$ \\
\hline $\begin{array}{l}\text { Acute ischaemic } \\
\text { heart disease }\end{array}$ & $31(3)$ & $11(1)$ & Others & $26(6)$ & $12(5)$ & & & & Other diagnoses & $3(5)$ & $4(14)$ \\
\hline $\begin{array}{l}\text { Deep vein } \\
\text { thrombosis UNS }\end{array}$ & $13(1)$ & $19(1)$ & & & & & & & & & \\
\hline Mitral stenosis & $21(2)$ & $2(<1)$ & & & & & & & & & \\
\hline $\begin{array}{l}\text { Hypertensive heart } \\
\text { disease }\end{array}$ & $20(2)$ & $1(<1)$ & & & & & & & & & \\
\hline Cardiac arrest & $2(<1)$ & $16(1)$ & & & & & & & & & \\
\hline Other & $113(11)$ & $134(8)$ & & & & & & & & & \\
\hline
\end{tabular}


$4540 / 6961$ inpatients $(65 \%)$ in the TH and 8900/13 342 $(67 \%)$ in the NTH (table 2). An average of eight and five prescribing occasions were found per patient at the TH and NTH, respectively. Overall, a significantly higher proportion of the antibiotics prescribed in the TH adhered to the NLEMI: $77 \%$ prescriptions (27 640/ $35732)$ than in the NTH: 60\% (24683/41 068, $\mathrm{p}<0.001)$.

Seven per cent of antibiotics in the $\mathrm{TH}$ were prescribed using generic names, which was significantly higher than in the NTH $(2 \%, \mathrm{p}<0.001)$. Some antibiotics were prescribed using trade names at the $\mathrm{TH}$-for example, 'Cipro', 'Doxy', 'Genta' and 'Metrogyl'. However, these were local abbreviations devised by the staff for ciprofloxacin, doxycycline, gentamycin and metronidazole, respectively. Even though these four antibiotics were prescribed using trade names, generic antibiotics were dispensed from the hospital pharmacy. A longer duration of stay and longer duration of antibiotic treatment was observed at the TH (mean days: 6 and 6, respectively) than at the NTH (mean days: 3 and 4, respectively, $\mathrm{p}<0.001)$.

\section{Distribution of inpatients in groups (a) and (b) and antibiotic prescription patterns}

Cardiovascular diseases accounted for $48 \%$ of patients in group (a) and (b) at the TH and $30 \%$ at the NTH. In the non-bacterial fever group, malaria was significantly more common at the NTH $(74 \%)$ and viral fever was significantly more common at the TH $(66 \%, \mathrm{p}<0.001$, table 1$)$.

Broad-spectrum antibiotics such as third-generation cephalosporins (J01DD) and FDCs (J01RA*) comprised $52 \%$ of the prescribing occasions at the NTH, of which FDCs accounted for approximately half (table 3). These classes accounted for $13 \%$ of total prescribing occasions and $<1 \%$ FDCs. At the NTH, cephalosporins (thirdgeneration cephalosporins J01DD, >30\%) were most commonly prescribed for the cardiovascular diseases $(>35 \%)$, followed by FDCs $(>20 \%)$. Fluoroquinolones $(\mathrm{J} 01 \mathrm{M})$ was the most commonly prescribed antibiotic class in the TH in both (a) and (b) groups (>30\% and $>40 \%$, respectively).

Third-generation cephalosporins (J01DD) constituted $47 \%$ and $30 \%$ of the prescriptions in subgroup 3 and 4 at the NTH, followed by FDCs (19\% and $29 \%$ of the prescriptions, respectively). Overall, antibiotic prescriptions were significantly more common for the patients in subgroup 3 than in the subgroup $1^{\prime}(p<0.001)$. The type of malaria was verified by blood sample reports in some cases of subgroup 3 (TH: $4 \%$ and NTH: $7 \%$ ). None of the records from the four subgroups showed a requisition for samples to be sent for bacterial culture and a susceptibility test.

Ciprofloxacin (J01MA02) was the most frequently prescribed antibiotic substance measured in DDD/1000 patients at the TH and ceftriaxone (J01DD04, table 4) at the NTH. The highest number of prescribed DDDs/1000 patients was recorded for ciprofloxacin, followed by doxycycline and ceftriaxone in both hospitals (figure 2).

\section{DISCUSSION}

To our knowledge this study is the first to investigate and present antibiotic prescription practices at medicine departments in Indian private sector hospitals by focusing on non-bacterial infectious diseases. This is a limitation, as the results of this study could not be compared with the findings of any other study. Thus the our results were compared with the most equivalent studies available globally.

Antibiotics were commonly prescribed to inpatients at both study hospitals. Irrespective of the indications, broad-spectrum antibiotics and third-generation cephalosporins, which should be conserved for high-risk comorbidities and life-threatening bacterial infections, were prescribed frequently. This study also highlights the high rates of antibiotic prescriptions used to treat selected groups of non-bacterial infectious diseases, such as cardiovascular disease, malaria and viral fever.

\section{Antibiotic prescriptions in the cardiovascular and fever groups}

The average percentages of patients who were prescribed antibiotics in the medicine departments were similar (TH: $65 \%$ and NTH: $67 \%, \mathrm{p}<0.001$ ) in comparison with the rates in the medicine department of a public hospital at Bathalapalli, Andhra Pradesh, India $(63 \%) .{ }^{26}$ With a few exceptions, such as rheumatic fever, endocarditis, pericarditis and myocarditis (bacterial or viral), cardiovascular diseases are primarily noninfectious. COPD and RHD are diseases commonly found in patients with cardiovascular disease. Rheumatic fever is an immune response sequel to an infection and may cause endocarditis. ${ }^{23}{ }^{27}$ However, pericarditis and myocarditis most commonly develop from viral pathogens, for which antibiotic treatment is not a routine recommendation. $^{28} 29$

Interestingly, more than $35 \%$ of inpatients among the 'cardiovascular group with no registered bacterial infection' were prescribed antibiotics at both hospitals. In accordance with treatment guidelines and recommendations, only patients who have a confirmed infectious diagnosis are expected to be given an antibiotic prescription. $^{30-32}$ Nonetheless, empirical or presumptive antibiotic therapy is also accepted when the clinical diagnosis, based on the presence of a strong clinical suspicion of bacterial infection, is substantiated by relevant medical history and clinical findings. ${ }^{30}$ According to the WHO and the Indian National Treatment Guidelines for Antimicrobial Use, presumptive therapy is typically a one-time treatment given for clinically presumed infection while waiting for the culture report. ${ }^{31}{ }^{32}$ A combination of the clinical findings-laboratory and radiological reports-is considered to confirm the diagnosis and lead to definitive treatment. ${ }^{32}$ 
Table 2 Demographic details and antibiotic prescribing information of the inpatients in the medicine departments of one teaching and one non-teaching hospital in Ujjain, India

\begin{tabular}{|c|c|c|c|c|c|c|c|c|c|c|c|c|c|c|c|}
\hline & \multicolumn{3}{|c|}{ Medicine department } & \multicolumn{3}{|c|}{$\begin{array}{l}\text { Cardiovascular with no } \\
\text { registered bacterial } \\
\text { diagnosis Subgroup } 1\end{array}$} & \multicolumn{3}{|c|}{$\begin{array}{l}\text { Cardiovascular with } \\
\text { suspected bacterial } \\
\text { infection Subgroup } 2\end{array}$} & \multicolumn{3}{|c|}{$\begin{array}{l}\text { Malaria or viral fever with } \\
\text { no registered bacterial } \\
\text { diagnosis Subgroup } 3\end{array}$} & \multicolumn{3}{|c|}{$\begin{array}{l}\text { Malaria or viral fever } \\
\text { with suspected bacterial } \\
\text { infection Subgroup } 4\end{array}$} \\
\hline & $\overline{\mathrm{TH}}$ & NTH & p Value & TH & NTH & p Value & $\overline{\mathrm{TH}}$ & NTH & p Value & $\overline{\mathrm{TH}}$ & NTH & p Value & TH & NTH & p Value \\
\hline Inpatients, $\mathrm{n}$ & 6961 & 13342 & & 1068 & 1738 & & 438 & 254 & & 693 & 1177 & & 55 & 28 & \\
\hline $\begin{array}{l}\text { Age (years), } \\
\text { mean (SD) }\end{array}$ & $45(17)$ & $43(18)$ & $<0.001$ & $53(14)$ & $55(15)$ & $<0.001$ & $49(17)$ & $51(17)$ & 0.222 & $36(15)$ & $35(16)$ & 0.387 & $37(14)$ & $40(20)$ & 0.440 \\
\hline $\begin{array}{l}\text { Inpatients } \\
\text { prescribed ABs, } \\
\text { n (\%) }\end{array}$ & $4540(65)$ & $8900(67)$ & 0.034 & $392(37)$ & $808(46)$ & $<0.001$ & $299(68)$ & $179(70)$ & 0.545 & $569(82)$ & $831(71)$ & $<0.001$ & $53(96)$ & $21(75)$ & $0.006^{\star}$ \\
\hline $\begin{array}{l}\text { Duration of } \\
\text { hospital stay } \\
\text { (days), } \\
\text { mean (SD) }\end{array}$ & $6(5)$ & $3(3)$ & $<0.001$ & $6(5)$ & $3(3)$ & $<0.001$ & $7(5)$ & $4(3)$ & $<0.001$ & $4(4)$ & $3(2)$ & $<0.001$ & $5(3)$ & $4(2)$ & 0.796 \\
\hline $\begin{array}{l}\text { Duration of } A B \\
\text { treatment (days), } \\
\text { mean (SD) }\end{array}$ & $6(4)$ & $4(2)$ & $<0.001$ & $6(4)$ & $4(2)$ & $<0.001$ & $7(4)$ & $4(2)$ & $<0.001$ & $5(3)$ & $4(2)$ & $<0.001$ & $5(2)$ & $5(2)$ & 0.419 \\
\hline $\begin{array}{l}\text { Total } A B \\
\text { prescription, } n\end{array}$ & 35732 & 41068 & & 2741 & 3366 & & 2388 & 855 & & 3210 & 3451 & & 316 & 128 & \\
\hline $\begin{array}{l}\text { Prescriptions per } \\
\text { patient }\end{array}$ & 7.9 & 4.6 & & 7 & 4 & & 8 & 4.8 & & 5.6 & 4.2 & & 6 & 6.1 & \\
\hline $\begin{array}{l}\text { AB prescriptions } \\
\text { by generic } \\
\text { name, } n(\%)\end{array}$ & $2341(7)$ & $685(2)$ & $<0.001$ & $175(6)$ & $47(1)$ & $<0.001$ & $282(12)$ & $46(5)$ & $<0.001$ & $61(2)$ & $52(2)$ & 0.214 & $19(6)$ & $5(4)$ & $0.374^{\star}$ \\
\hline $\begin{array}{l}\text { Prescriptions of } \\
\text { AB found in } \\
\text { NLEMI, } n(\%)\end{array}$ & $\begin{array}{l}27640 \\
(77)\end{array}$ & $\begin{array}{l}24683 \\
(60)\end{array}$ & $<0.001$ & - & - & - & - & - & - & - & - & - & - & - & - \\
\hline
\end{tabular}


Table 3 Distribution of prescribed antibiotics according to class in four selected diagnoses groups at one teaching and one mon-teaching hospital in Ujjain, India

\begin{tabular}{|c|c|c|c|c|c|c|c|c|c|c|c|c|}
\hline \multirow[b]{2}{*}{ Name of AB; ATC code } & \multicolumn{3}{|c|}{$\begin{array}{l}\text { Cardiovascular with no } \\
\text { registered bacterial infection } \\
\text { Subgroup } 1\end{array}$} & \multicolumn{3}{|c|}{$\begin{array}{l}\text { Cardiovascular with } \\
\text { suspected bacterial } \\
\text { infection Subgroup } 2\end{array}$} & \multicolumn{3}{|c|}{$\begin{array}{l}\text { Malaria or viral fever with no } \\
\text { registered bacterial infection } \\
\text { Subgroup } 3\end{array}$} & \multicolumn{3}{|c|}{$\begin{array}{l}\text { Malaria or viral fever with } \\
\text { suspected bacterial } \\
\text { infection Subgroup } 4\end{array}$} \\
\hline & $\begin{array}{l}\mathrm{TH} \\
\mathrm{n}(\%)\end{array}$ & $\begin{array}{l}\text { NTH } \\
\text { n (\%) }\end{array}$ & $\mathrm{p}$ Value & $\begin{array}{l}\text { TH } \\
\mathrm{n}(\%)\end{array}$ & $\begin{array}{l}\text { NTH } \\
\text { n (\%) }\end{array}$ & $p$ Value & $\begin{array}{l}\text { TH } \\
\text { n (\%) }\end{array}$ & $\begin{array}{l}\text { NTH } \\
\text { n (\%) }\end{array}$ & $p$ Value & $\begin{array}{l}\mathrm{TH} \\
\mathrm{n}(\%)\end{array}$ & $\begin{array}{l}\text { NTH } \\
\text { n (\%) }\end{array}$ & p Value \\
\hline Total prescriptions & 2741 & 3366 & & 2388 & 855 & & 3210 & 3451 & & 316 & 128 & \\
\hline Tetracyclines; J01A; J01AA & $284(10)$ & $5(0)$ & $<0.001$ & $243(10)$ & $0(0)$ & & $553(17)$ & $75(2)$ & $<0.001$ & $83(26)$ & $0(0)$ & \\
\hline$\beta$-Lactam ABs, penicillin; J01C & 456 (17) & 498 (15) & 0.041 & $622(26)$ & $184(22)$ & 0.009 & $111(3)$ & $245(7)$ & $<0.001$ & $12(4)$ & 7 (5) & 0.431 \\
\hline $\begin{array}{l}\text { Extended-spectrum penicillins; } \\
\text { J01CA }\end{array}$ & $83(3)$ & 99 (3) & 0.843 & $122(5)$ & 99 (12) & $<0.001$ & $19(1)$ & $51(1)$ & $<0.001$ & $0(0)$ & $2(2)$ & \\
\hline $\begin{array}{l}\text { Combination of penicillin including } \\
\beta \text {-lactamase AB; J01CR }\end{array}$ & $373(14)$ & 399 (12) & 0.040 & $500(21)$ & $85(10)$ & $<0.001$ & $92(3)$ & $194(6)$ & $<0.001$ & $12(4)$ & $5(4)$ & $1.0 \dagger$ \\
\hline Other $\beta$-lactams; J01D & $496(18)$ & $1391(41)$ & $<0.001$ & $353(15)$ & $304(36)$ & $<0.001$ & $665(21)$ & $1792(52)$ & $<0.001$ & $40(13)$ & $39(30)$ & $<0.001$ \\
\hline $\begin{array}{l}\text { 1st-generation cephalosporins; } \\
\text { J01DB }\end{array}$ & $7(0)$ & $16(1)$ & 0.163 & $0(0)$ & $5(1)$ & & $0(0)$ & $9(0)$ & & $0(0)$ & $0(0)$ & \\
\hline $\begin{array}{l}\text { 2nd-generation cephalosporins; } \\
\text { J01DC }\end{array}$ & $0(0)$ & $98(3)$ & & $0(0)$ & 27 (3) & & $0(0)$ & $168(5)$ & & $0(0)$ & $0(0)$ & \\
\hline $\begin{array}{l}\text { 3rd-generation cephalosporins; } \\
\text { J01DD }\end{array}$ & $481(18)$ & $1254(37)$ & $<0.001$ & $353(15)$ & 272 (32) & $<0.001$ & $665(21)$ & $1606(47)$ & $<0.001$ & 40 (13) & $39(30)$ & $<0.001$ \\
\hline $\begin{array}{l}\text { 4th-generation cephalosporins; } \\
\text { J01DH }\end{array}$ & $8(0)$ & $23(1)$ & 0.032 & $0(0)$ & $0(0)$ & & $0(0)$ & $9(0)$ & & $0(0)$ & $0(0)$ & \\
\hline $\begin{array}{l}\text { Sulfonamide with timethoprim; J01E: } \\
\text { J01EE }\end{array}$ & $8(0)$ & $0(0)$ & & $18(1)$ & $0(0)$ & & $8(0)$ & $0(0)$ & & $0(0)$ & $0(0)$ & \\
\hline Macrolides, lincosamides; J01F & $16(1)$ & $2(0)$ & $<0.001$ & $4(0)$ & $6(1)$ & 0.025 & $15(0)$ & $7(0)$ & 0.060 & $3(1)$ & $4(3)$ & $0.110 \dagger$ \\
\hline Macrolides; J01FA & $12(0)$ & 2 & 0.002 & $4(0)$ & $6(1)$ & & $15(0)$ & $7(0)$ & & $3(1)$ & $4(3)$ & \\
\hline Lincosamides; J01FF & $4(0)$ & $0(0)$ & & $0(0)$ & $0(0)$ & & $0(0)$ & $0(0)$ & & $0(0)$ & $0(0)$ & \\
\hline Aminoglycoside; J01G: J01GB & 78 (3) & $73(2)$ & 0.090 & $149(6)$ & $46(5)$ & 0.364 & 17 (1) & $60(2)$ & $<0.001$ & 11 (3) & $9(7)$ & 0.102 \\
\hline Quinolones; J01M: J01MA & 1031 (38) & $301(9)$ & $<0.001$ & 731 (31) & $112(13)$ & $<0.001$ & $1526(48)$ & 464 (13) & $<0.001$ & $126(40)$ & 37 (29) & 0.030 \\
\hline $\begin{array}{l}\text { Fixed-dose combination of ABs; } \\
\text { J01R: J01RA* }\end{array}$ & $12(0)$ & 929 (28) & $<0.001$ & $31(1)$ & $170(20)$ & $<0.001$ & 34 (1) & 669 (19) & $<0.001$ & $6(2)$ & $17(13)$ & $<0.01$ \\
\hline Other ABs; J01X & $167(6)$ & $176(5)$ & 0.145 & $132(6)$ & $30(4)$ & 0.020 & $149(5)$ & $138(4)$ & 0.197 & $20(6)$ & $15(12)$ & 0.056 \\
\hline Glycopetide ABs; J01XA & $15(1)$ & $176(5)$ & $<0.001$ & $0(0)$ & $0(0)$ & & $0(0)$ & $0(0)$ & & $0(0)$ & $0(0)$ & \\
\hline Imidazole derivatives; J01XD & $152(6)$ & $0(0)$ & & $132(6)$ & $30(4)$ & 0.020 & $149(5)$ & $137(4)$ & 0.176 & $20(6)$ & $15(12)$ & 0.056 \\
\hline Other ABs; J01XX & $0(0)$ & $0(0)$ & & $0(0)$ & $0(0)$ & & $0(0)$ & $1(0)$ & & $0(0)$ & $0(0)$ & \\
\hline $\begin{array}{l}\text { Drugs for treatment of tuberculosis; } \\
\text { J04A }\end{array}$ & $0(0)$ & $0(0)$ & & 24 (1) & $0(0)$ & & 0 & $0(0)$ & & $0(0)$ & $0(0)$ & \\
\hline $\begin{array}{l}\text { Antibiotics; J04AB (treatment for } \\
\text { tuberculosis) }\end{array}$ & $0(0)$ & $0(0)$ & & $6(0)$ & $0(0)$ & & $0(0)$ & $0(0)$ & & $0(0)$ & $0(0)$ & \\
\hline
\end{tabular}




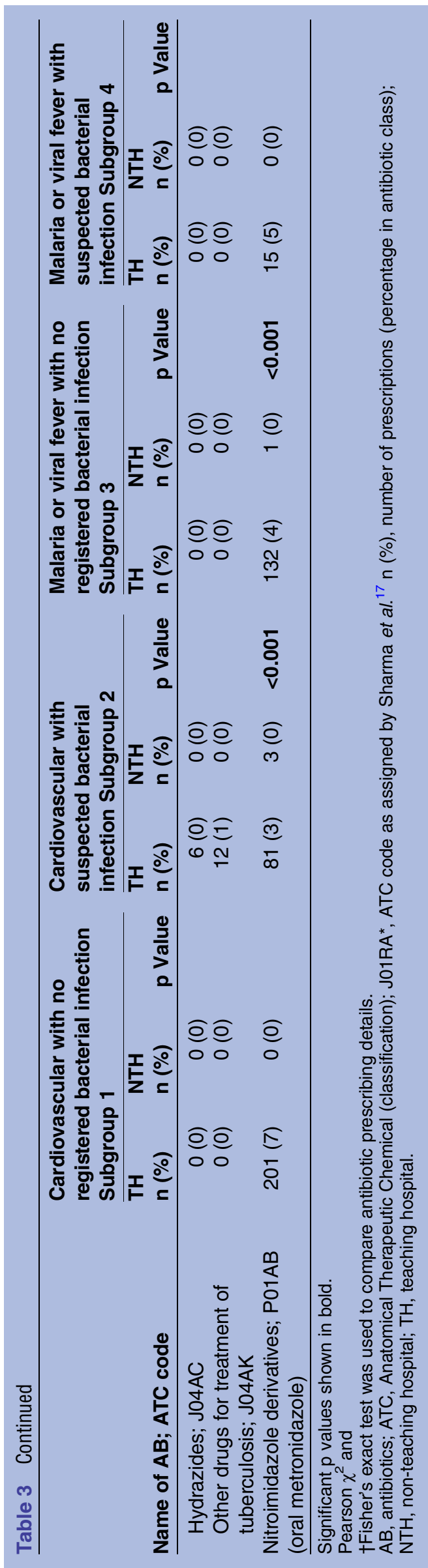

Microbiology laboratories were highly underused in both study hospitals. None of the patient records in the selected four subgroups included notes about sending samples for culture and susceptibility testing. Therefore, the practice of prescribing antibiotics to patient groups with no registered bacterial infection in the absence of laboratory confirmation could not be considered to be rational. Among the patients with COPD and RHD, the aetiology of the current episode of hospitalisation could potentially be expected to be non-bacterial (eg, viral infection). However, this could not be confirmed owing to the absence of laboratory investigations. It is worth mentioning here that prolonged empirical antibiotic treatment without a clear evidence of infection is one of the causes of the development of antibiotic resistance.

More FDCs were prescribed to the cardiovascular patients at the NTH than at the TH. The rationality of the newer FDCs coded with ATC code: J01RA* has not yet been established and these combinations are not listed in either the NLEMI or WHOLEM. ${ }^{18}{ }^{19}$ It is also evident that the constituents of these combinations are often present in lower quantities than is recommended, which might lead to the development of antibiotic resistance. ${ }^{33}$

The subgroup 'malaria or viral fever with suspected bacterial infection' was found to have the highest rate of antibiotic prescriptions among all the four subgroups (TH: 96\%, NTH: 75\%). Our results also show that patients with fever were more likely to receive antibiotic prescriptions than patients with cardiovascular diseases. Fever is a common symptom of malaria, viral fever and bacterial infection. Therefore, the doctors might have prescribed antibiotics as a 'prophylactic' treatment to treat bacterial infection, if any. In our study the rate of antibiotic prescriptions for patients with fever was higher than, yet comparable to, a study at primary and secondary healthcare settings in Uttar Pradesh, India, where $85 \%$ of the patients with fever were prescribed antibiotics. ${ }^{34}$ Additionally, in our study a high percentage of patients with fever (malaria or viral fever) with 'no registered bacterial infection' were prescribed antibiotics (TH: $82 \%$, NTH: 71\%). An outpatient study from Uganda, a malaria-endemic country, showed that $42 \%$ of patients with malaria were prescribed antibiotics without any registered indication. ${ }^{25}$ As the majority of the prescriptions in our study were empirical, the rationale for using the antibiotics cannot be evaluated. However, prescribing antibiotics to treat non-bacterial infections is considered to be an irrational practice. Thus it is imperative that this matter be addressed.

\section{Adherence to the essential medicine lists and prescriptions by generic name}

A higher proportion of prescribed antibiotics at the $\mathrm{TH}$ $(77 \%)$ than at the NTH $(60 \%)$ were from the NLEMI $(\mathrm{p}<0.001)$. This might be attributable to a management policy at the $\mathrm{TH}$ to purchase and supply medicines. However, there is a need to improve adherence to the NLEMI at both hospitals. According to WHO, prescribing 
Table 4 Most commonly prescribed antibiotics among the selected diagnoses groups presenting the prescribing occasions in DDDs/1000 patients at sixth level of the ATC classification

\begin{tabular}{|c|c|c|c|c|c|c|c|c|}
\hline \multirow[b]{2}{*}{ Name; ATC code } & \multicolumn{2}{|c|}{$\begin{array}{l}\text { Cardiovascular with no } \\
\text { registered bacterial } \\
\text { infection (Subgroup 1) } \\
\text { n (\%) }\end{array}$} & \multicolumn{2}{|c|}{$\begin{array}{l}\text { Cardiovascular with } \\
\text { suspected bacterial } \\
\text { infection (Subgroup 2) } \\
\text { n (\%) }\end{array}$} & \multicolumn{2}{|c|}{$\begin{array}{l}\text { Malaria or viral fever with } \\
\text { no registered bacterial } \\
\text { infection (Subgroup 3) } \\
\text { n (\%) }\end{array}$} & \multicolumn{2}{|c|}{$\begin{array}{l}\text { Malaria or viral fever with } \\
\text { suspected bacterial } \\
\text { infection (Subgroup 4) } \\
\text { n (\%) }\end{array}$} \\
\hline & TH & NTH & TH & NTH & $\overline{\mathrm{TH}}$ & NTH & $\overline{\mathrm{TH}}$ & NTH \\
\hline Total DDDs/1000 patients & $2062\left(99^{\#}\right)$ & $1456(100)$ & $4514\left(99^{\#}\right)$ & $3421(100 \dagger)$ & $4480(100 \dagger)$ & $3048(100 \dagger)$ & $5432(100 \dagger)$ & $5827(100)$ \\
\hline Doxycycline, J01AA02 & $491(24)$ & & $1030(23)$ & & $1463(33)$ & $296(10)$ & $2745(51)$ & \\
\hline Ampicillin, J01CA01 & $68(3)$ & & $170(4)$ & & & & & \\
\hline Amoxicillin, J01CA04 & & $81(6)$ & & $435(13)$ & & & & \\
\hline Amoxicillin+clavulanic acid, J01CR02 & & & & $566(17)$ & & $88(3)$ & & \\
\hline Piperacillin+tazobactam, J01CR05 & & & & & & $34(1)$ & & \\
\hline Ampicillin+cloxacillin, J01CR50 & $217(11)$ & & $774(17)$ & & & & $191(4)$ & \\
\hline Cefuroxime, J01DC02 & & & & $95(3)$ & & $136(4)$ & & \\
\hline Cefprozil, J01DC10 & & $75(5)$ & & & & & & \\
\hline Cefotaxime, J01DD01 & $172(8)$ & $46(3)$ & $298(7)$ & $59(2)$ & $199(4)$ & $96(3)$ & $295(5)$ & \\
\hline Ceftriaxone, J01DD04 & $133(6)$ & $558(38)$ & $244(5)$ & $907(27)$ & $560(13)$ & $1052(35)$ & $164(3)$ & $1402(24)$ \\
\hline Azithromycin, J01FA10 & & & & & & & & $476(8)$ \\
\hline Gentamicin, J01GB03 & $44(2)$ & & $167(4)$ & $81(2)$ & & & & \\
\hline Amikacin, J01GB06 & & & & & & & & $321(6)$ \\
\hline Ofloxacin, J01MA01 & & & & & & $202(7)$ & & \\
\hline Ciprofloxacin, J01MA02 & $687(33)$ & $141(10)$ & $1057(23)$ & $527(15)$ & $1940(43)$ & $602(20)$ & $1185(22)$ & $2886(50)$ \\
\hline Norfloxacin, J01MA06 & & & $201(4)$ & & & & $273(5)$ & \\
\hline Levofloxacin, J01MA12 & & $73(5)$ & $202(4)$ & $129(4)$ & & & $145(3)$ & \\
\hline Cefoperazone+sulbactam, J01RA*83 & & $92(6)$ & & $94(3)$ & & $90(3)$ & & $125(2)$ \\
\hline Ceftriaxone+sulbactam, J01RA*84 & & $228(16)$ & & $277(8)$ & & $199(7)$ & & \\
\hline Ceftriaxone+tazobactam, J01RA*85 & & $162(11)$ & & $156(5)$ & & $162(5)$ & & $250(4)$ \\
\hline Metronidazole, J01XD01 & $139(7)$ & & $262(6)$ & $95(3)$ & $204(5)$ & $91(3)$ & $262(5)$ & $367(6)$ \\
\hline Metronidazole, P01AB01 (Oral) & $111(5)$ & & $109(2)$ & & $114(3)$ & & $172(3)$ & \\
\hline
\end{tabular}

\#Total percentage of most commonly prescribed antibiotics is $99 \%$.

tRounding off the percentages to nearest integer made the total more than $100 \%$.

ATC, Anatomical Therapeutic Chemical; DDD, defined daily dose; $n$ (\%), number of prescriptions (percentage); NTH, non-teaching hospital; TH, teaching hospital. 
3500

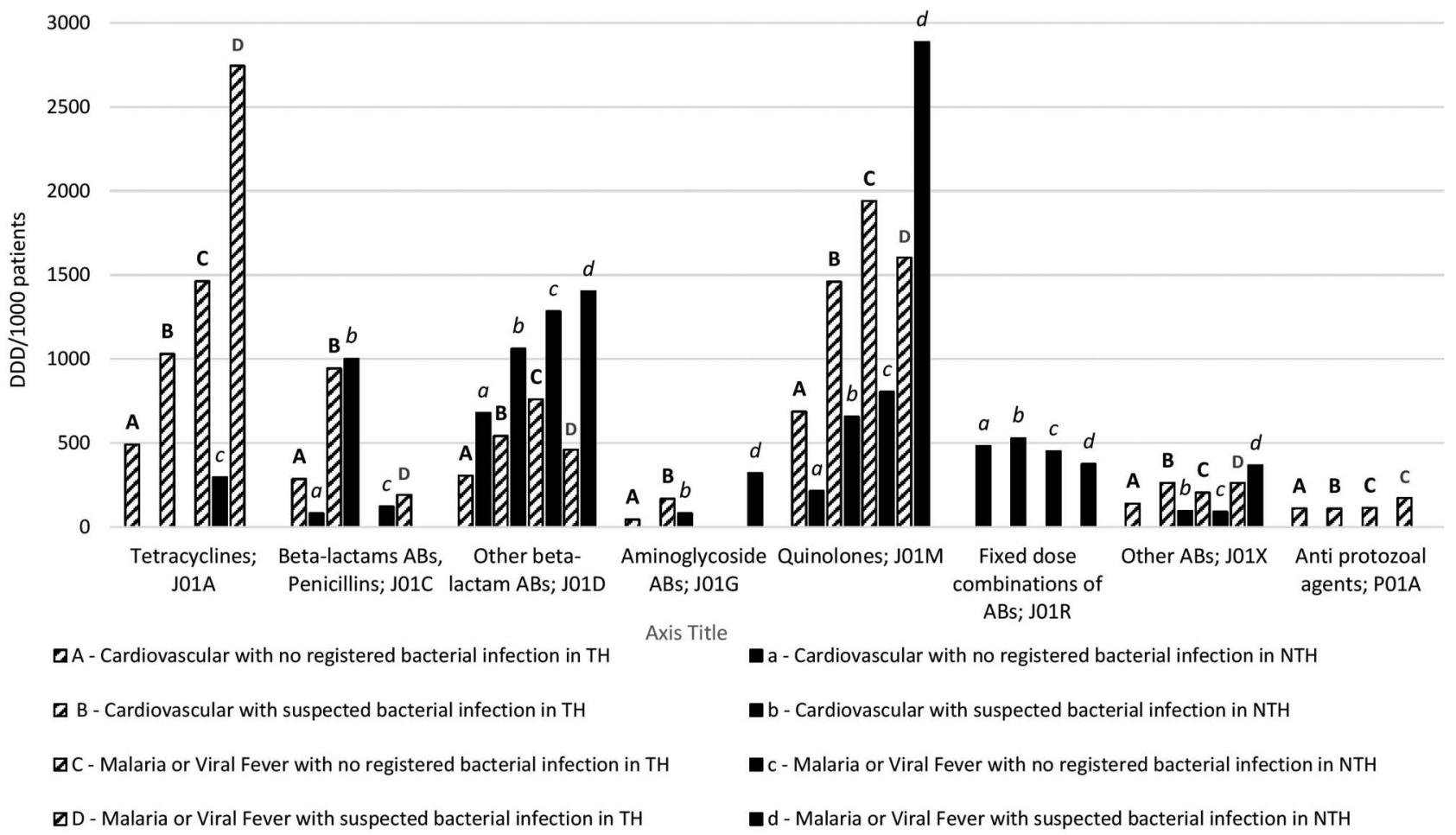

Figure 2 Top 90\% of prescription in the four selected groups measured in defined daily dose (DDD)/1000 patients, presented at fourth level of the Anatomical Therapeutic Chemical (ATC) classification at one teaching and one non-teaching hospitals in Ujjain, India. ABs, antibiotics; NTH, non-teaching hospital; TH, teaching hospital.

drugs by their generic name is part of rational prescribing, is cost-effective and provides flexibility, allowing purchase of the drug from any company. This policy is equally applicable to both public and private healthcare settings. However, adherence to this policy is greater at public hospitals, followed by 'private non-profit' hospitals and by the 'private for-profit' hospitals. ${ }^{13} 1435$

In our study, a significantly lower proportion of antibiotic prescriptions were made by generic name for the patients of subgroup 1 (TH: $6 \%$, NTH: $1 \%$ p $<0.001$ ) or subgroup 2 (TH: $12 \%$ NTH: $5 \% \mathrm{p}<0.001$ ) at the NTH than at the TH. Third-generation cephalosporins (J01D, $29 \%$ ) and FDCs (J01RA*, 23\%) were the most commonly prescribed classes of antibiotics at the NTH, whereas quinolones were most commonly prescribed at the TH (J01M, 37\%, NTH: 13\%). Previous studies from Uttar Pradesh, India and Madhya Pradesh, India have also shown similar results for academic and nonacademic hospitals. ${ }^{13} 1417$ The high incidence of prescribing these classes is further supported by Van Boeckel et al, who observed a significant increase in the consumption of fluoroquinolones and cephalosporins globally over the past decade. This increase was mainly attributed to the increased rates in India and China. ${ }^{9}$

At the NTH, prescriptions of FDCs varied between $19 \%$ and $28 \%$ among the selected subgroups (TH: $<2 \%)$ and the prescriptions of third-generation cephalosporins varied between $30 \%$ and $47 \%$ (TH: $<22 \%$ ). According to $\mathrm{WHO}$, prescribing multiple antibiotics when not indicated, often combined in inadequate doses (smaller or larger quantity than recommended), and prescription of drugs other than local or national guidelines are all examples of actions deemed inappropriate. ${ }^{36}$ All these practices could be seen in prescribing newer FDCs (J01RA*); both of the study hospitals are from the private sector and are regulated by the same trust on a 'not for-profit' basis. The differences in the prescribing practices might be due to each hospital's policy and because academic hospitals are part of the educational process, and regular educational activities conducted at these hospitals result in better adherence to the guidelines, as seen at the TH.

Another reason for the frequent prescribing of broadspectrum antibiotics, new FDCs and use of trade names at the NTH could be explained by the results of a review conducted by Blumenthal. ${ }^{37}$ That review concluded that physicians who had received gifts or money from pharmaceutical companies were more likely to prescribe drugs by brand names and less likely to use the generic names. The pressure on doctors at the NTH might be expected, owing to unrestricted visits from pharmaceutical company representatives. ${ }^{37}$ Moreover, these new FDCs of antibiotics are more expensive than the regular and generic formulations. ${ }^{13}{ }^{14} 37$ Restriction of these 
visits and management control over the purchase and supply of medicines are probably the main reasons for the low incidence of prescribing FDCs and the high use of generic drugs at the TH.

Interestingly, trade names were used as local abbreviations to prescribe the four most commonly prescribed antibiotics: ciprofloxacin, doxycycline, gentamycin and metronidazole, at the $\mathrm{TH}$, as discussed in the 'Results' section. However, only generic drugs were purchased and dispensed at the $\mathrm{TH}$ owing to administrative control over the purchase and supply of the drugs. Thus even if these antibiotics were prescribed using an abbreviation similar to the trade name, they were included in the generic name prescribing category.

\section{Duration of hospital stay and of antibiotic treatment}

In this study both the duration of hospital stay and the duration of antibiotic treatment were longer at the $\mathrm{TH}$ than the NTH among all inpatients groups, possibly because patients at the TH received free healthcare services and drugs, making their stay economically feasible. In contrast, at the NTH, patients had to pay for all the services and drugs they received. This association of longer duration of stay and antibiotic treatment at $\mathrm{TH}$ has also been found in previous studies from India. ${ }^{13} 14{ }^{17}$ However, it is evident that treatment given for a period that is either shorter or longer than recommended, is inappropriate, and contributes substantially to the development of antibiotic resistance. ${ }^{136}$

The absence of computerised record systems in hospitals and of personal identification numbers, untrained staff and high staff turnover make a detailed study like this time consuming and onerous and delays the analysis. We are aware that extensive manual checking and adding the ICD codes and ATCs for the new FDCs to the data have prolonged the analysis and delayed the presentation. However, use of man power is the only option to conduct such detailed studies at resource constrained settings but at the same time leads to a more accurate description of the prescribing patterns.

\section{Strengths and limitations}

A large number of patients were screened over a 3-year period; this obviates seasonal variations in infectious aetiology, which would affect antibiotic prescribing. The same form was used for the data collection and the process was supervised and monitored by same person at both hospitals to improve the reliability of the data. The diagnoses were not verified externally, which is a limitation of the study. However, external verification is virtually inapplicable to studies that rely upon the routine collection of data. The results of the study were based on the notes included in the patient files. Extensive efforts were made to document all notes, including diagnoses written in the patient files. However, the possibility that a few diagnoses were missed and some data lost during the transition from the forms to digital storage cannot be excluded.

\section{CONCLUSION}

A greater number of prescribing occasions were recorded at the TH, but not at the NTH, than advised by the guidelines. However, overall adherence was low. Fever was a factor leading to antibiotic prescription at both hospitals. Patients with non-bacterial infections, such as malaria or viral fever, or with cardiovascular diseases were prescribed antibiotics at both medicine departments, which could not be justified. Broad-spectrum antibiotics with irrational combinations of antibiotics were commonly prescribed in the study hospitals for non-indicated conditions. A large proportion of patients were categorised as having suspected bacterial diagnoses (subgroups 2 and 4). If microbiology reports could have confirmed the aetiology, some of these might have been categorised in the non-bacterial group and might have contributed to higher antibiotic prescribing rates in the non-bacterial diagnoses (subgroups 1 and 3). However, this was not possible owing to the absence of confirmed aetiology and the nature of the study design (observational).

\section{GENERALISABILITY AND FUTURE IMPLICATIONS}

The data collection method used in the study is robust and reliable. In accordance with one of the WHO goals of the 'Global Action Plan' and in view of limited knowledge of antibiotic use and resistance patterns, our study suggests that there is a need to conduct similar long-term surveillance studies globally and share the results. The data collection method and tested tool used in the study could easily be adapted in other settings that lack computerised patient records. The management at the TH had a policy of controlling the purchase and supply of medicines. This control had a positive effect at the TH in comparison with the NTH, minimising antibiotic prescribing and resulting in better adherence to the NLEMI and the use of generic names. This control could be implemented and tested in other constrained settings. The recruitment of nursing staff who routinely work in the department for manual data collection would have helped to minimise the influence on the prescribers. High prescribing rates of antibiotics and use of FDCs among inpatients in these settings are broadly representative of practices of similar healthcare settings in low-middle income countries. Another important issue raised in the study is lack of use of microbiology facilities for culture and susceptibility testing, which is of utmost importance. The need to develop and implement local diagnosis-specific prescribing guidelines in conjunction with continuous follow-up is also emphasised by our study. Physicians should be motivated to send samples for culture before prescribing antibiotics. Improving hygiene practices is another recommendation that would prevent the spread of infection and reduce the 'prophylactic' use of antibiotics.

\section{Author affiliations}

${ }^{1}$ Department of Public Health Sciences, Global Health-Health Systems and Policy (HSP): Medicines, focusing antibiotics, Karolinska Institutet, Stockholm, Sweden 
${ }^{2}$ Department of Medicine, Ruxmaniben Deepchand Gardi Medical College, Ujjain, India

${ }^{3}$ Department of Pharmacology, Ruxmaniben Deepchand Gardi Medical College, Ujjain, India

Acknowledgements The authors all the nurses and the management of both hospitals for their support and help during the study.

Contributors MS and CSL designed, visualised the research question and developed the data collection tool. MS conducted repeated training sessions for nursing personal for recording the data; was responsible for coordination with the nursing staff, monitoring and supervision of the data collection and entry. CSL participated in planning the study design and coordination of the study. KL, CSL and MS participated in the conception and design of the study and revising the paper critically for substantial intellectual content. KL grouped and analysed the data, performed the statistical analysis and contributed to drafting of the manuscript together with MS, CSL, FJ and AS. $\mathrm{KL}, \mathrm{AS}$ and MS were responsible for categorisation of the patients. All authors read and approved the final version of the manuscript.

Funding This study was supported by the Swedish Research Council (K200770X-20514-01-3 and K2013-70X-20514-07-5) and Asia Link (348 -2006 -6633). KL and FJ both received scholarships from Sida to visit the study settings. MS is a recipient of a scholarship from Erasmus Mundus External Cooperation Window Lot-15, India.

Competing interests None declared.

Provenance and peer review Not commissioned; externally peer reviewed.

Data sharing statement In accordance with institutional policy, the data are available at the institutional ethics committee. This is to protect the patient's confidentiality and to ensure the electronic security of the data. The data can be made available to all interested researchers on request from The Chairman, Ethics Committee, R.D. Gardi Medical College, Agar Road, Ujjain, Madhya Pradesh, India 456006 (email: iecrdgmc@yahoo.in, uctharc@sancharnet.in), giving all details of the article. The ethical approval number: 41/2007 needs to be quoted with the request.

Open Access This is an Open Access article distributed in accordance with the Creative Commons Attribution Non Commercial (CC BY-NC 4.0) license which permits others to distribute, remix, adapt, build upon this work noncommercially, and license their derivative works on different terms, provided the original work is properly cited and the use is non-commercial. See: http:// creativecommons.org/licenses/by-nc/4.0/

\section{REFERENCES}

1. World Health Organization. The evolving threat of antimicrobia resistance: options for action. WHO Publications. Geneva, 2014. http://whqlibdoc.who.int/publications/2012/9789241503181_eng.pdf (accessed 2016 Sep 15).

2. World Health Organization. The top 10 causes of death. Geneva 2014. http://www.who.int/mediacentre/factsheets/fs310/en/ (accessed 15 Sep 2016).

3. Ganguly NK, Arora NK, Chandy SJ, et al., Global Antibiotic Resistance Partnership (GARP) India Working Group. Rationalizing antibiotic use to limit antibiotic resistance in India. Indian J Med Res 2011;134:281-94.

4. Bhutta ZA, Sommerfeld J, Lassi ZS, et al. Global burden, distribution and interventions for infectious diseases of poverty. Infect Dis Poverty 2014;3:21.

5. Global Antibiotic Resistance Partnership (GARP) India Working Group. Antibiotic use and resistance in India. New Dehli, 2011. http:// www.cddep.org/publications?page $=1 \& f[0]=f i e l d \_r e g i o n: 13$ (accessed 15 Sep 2016).

6. World Health Organization. Disease and injury country estimates: burden of disease. Geneva. http://www.who.int/healthinfo/global burden_disease/estimates_country/en/index.html (accessed 16 Sep 2016).

7. Kumar SG, Adithan C, Harish BN, et al. Antimicrobial resistance in India: a review. J Nat Sci Biol Med 2013;4:286-91.
8. Wilcox MH, Freeman J, Fawley W, et al. Long-term surveillance of cefotaxime and piperacillin-tazobactam prescribing and incidence of Clostridium difficile diarrhoea. J Antimicrob Chemother 2004;54: 168-72.

9. Van Boeckel TP, Gandra S, Ashok A, et al. Global antibiotic consumption 2000 to 2010: an analysis of national pharmaceutical sales data. Lancet Infect Dis 2014;14:742-50.

10. The World Bank. World development indicators, GNI per capita, Atlas method. 2015. http://data.worldbank.org/indicator/NY.GNP. PCAP.CD (accessed 15 Sep 2016).

11. De Costa A, Diwan V. "Where is the public health sector?". Public and private sector healthcare provision in Madhya Pradesh, India. Health Policy (New York) 2007;84:269-76.

12. Sekher TV. Catastrophic health expenditure and poor in India : health insurance is the answer ? Vol. 494. SAGE-India, 2011:1-4. http://iussp.org/en/event/17/programme/paper/4043

13. Sharma M, Damlin AL, Sharma A, et al. Antibiotic prescribing in medical intensive care units-a comparison between two private sector hospitals in Central India. Infect Dis (Auckl) 2015;14:1-8.

14. Sharma M, Damlin A, Pathak A, et al. Antibiotic prescribing among pediatric inpatients with potential infections in two private sector hospitals in Central India. PLOS ONE 2015;10:e0142317.

15. WHO Int WG for Drug Statistics Methodology. Introduction to drug utilization research. Oslo, 2003:1-48. http://www.whocc.no/ filearchive/publications/drug utilization research.pdf (accessed 16 Sep 2016)

16. WHOCC. ATC/DDD Index. 2015. http://www.whocc.no/atc_ddd_ index/ (accessed 13 Mar 2015).

17. Sharma M, Eriksson B, Marrone G, et al. Antibiotic prescribing in two private sector hospitals; one teaching and one non-teaching: a cross-sectional study in Ujjain, India. BMC Infect Dis 2012;12:155.

18. Organization CDSC. National list of essential medicines. New Dehli, 2011. http://apps.who.int/medicinedocs/documents/s18693en/ s18693en.pdf (accessed 16 Sep 2016).

19. World Health Organization. Model list of essential medicines. Geneva, 2013:1-43. http://www.who.int/medicines/publications/ essentialmedicines/18th EML Final web 8Jul13.pdf (accessed 2016 Sep 16)

20. World Health Organization. The international statistical classification of diseases and health related problems, ICD-10. Malta: World Health Organization, 2012.

21. World Health Organization. International statistical classification of diseases and related health problems 10th Revision (ICD-10) version for 2010. http://apps.who.int/classifications/icd10/browse/ 2010/en

22. Enzler MJ, Berbari E, Osmon DR. Antimicrobial prophylaxis in adults. Mayo Clin Proc 2011;86:686-701.

23. Bisno A, Butchart EG, Ganguly NK, et al. Rheumatic fever and rheumatic heart disease. Who Tech Rep Ser 2001;923 (November 2001):1-122.

24. World Health Organization. Guidelines for the treatment of malaria 2nd edn. Geneva, 2010:197p. http://whqlibdoc.who.int/publications/ 2010/9789241547925_eng.pdf (accessed 13 Mar 2015).

25. Means AR, Weaver MR, Burnett SM, et al. Correlates of inappropriate prescribing of antibiotics to patients with malaria in Uganda. PLOS ONE 2014;9:1-7.

26. Alvarez-Uria G, Zachariah S, Thomas D. High prescription of antimicrobials in a rural district hospital in India. Pharm Pract (Granada) 2014;12:384

27. Habib G, Hoen B, Tornos P, et al. Guidelines on the prevention, diagnosis and treatment of infective endocarditis. Eur Heart $J$ 2009;30:2369-413.

28. Maisch B, Seferovic PM, Ristic AD, et al. Guidelines on the diagnosis and management of pericardial diseases: executive summary. Eur Heart J 2004;25:587-610.

29. Schultheiss HP, Khl U, Cooper LT. The management of myocarditis. Eur Heart J 2011;32:2616-25.

30. National Centre for Disease Control India. India national treatment guidelines for antimicrobial use in infectious diseases. Version 1.0. New Dehli, 2016:1-64. http://www.ncdc.gov.in/writereaddata/ linkimages/AMR_guideline7001495889.pdf

31. Bennet JE, Dolin R, Blaser MJ. Madell, Douglas and Bennet's principles and practice of infectious diseases. 8th edn. Philadelphia: Saunders, 2014

32. Davey P, Wilcox M, Irwing W, et al. Antimicrobial chemotherapy. 7th edn. Oxford: Oxford University Press, 2015. 
33. Tripathi K. Essentials of medical pharmacology. Antimicrobial drugs. 6th edn. New Dehli: Jaypee Brothers Medical Publishers, 2012.

34. Kumar R, Indira K, Rizvi A, et al. Antibiotic prescribing practices in primary and secondary health care facilities in Uttar Pradesh, India. $J$ Clin Pharm Ther 2008:33:625-34.

35. Pitaknetinan K, Tangcharoensathien V, Supachutikul A, et al. Profit, payment and pharmaceutical practices: perspectives from hospitals in Bangkok. Health Policy 1999;46:179-94. http://www.ncbi.nlm.nih. gov/pubmed/10351667

36. WHO. Promoting rational use of medicines: core components. WHO Policy Perspect Med 2002:1-6. http://apps.who.int/medicinedocs/pdf/ h3011e/h3011e.pdf

37. Blumenthal D. Doctors and drug companies. N Engl J Med 2004;351:1885-7. 